\title{
Genetic and genomic analyses of latent variables related to the milk fatty acid profile, milk composition, and udder health in dairy cattle
}

\author{
A. Cecchinato, ${ }^{1 *}$ N. P. P. Macciotta, ${ }^{2}$ M. Mele,${ }^{3}$ F. Tagliapietra, ${ }^{1}$ S. Schiavon, ${ }^{1}$ G. Bittante,${ }^{1}$ and S. Pegolo ${ }^{1}$ \\ ${ }^{1}$ Department of Agronomy, Food, Natural resources, Animals and Environment (DAFNAE), University of Padova, Viale dell'Università 16, \\ 35020 Legnaro, Padova, Italy \\ ${ }^{2}$ Dipartimento di Agraria, Sezione Scienze Zootecniche, Università di Sassari, Via de Nicola 9, 07100 Sassari, Italy \\ ${ }^{3}$ Dipartimento di Scienze Agrarie, Alimentari, Agro-ambientali, Università di Pisa, Via del Borghetto, 80, 56124 Pisa, Italy
}

\section{ABSTRACT}

The aim of this study was to perform genetic, genomewide association (GWAS), and gene-set enrichment analyses with latent variables related to milk fatty acid profile (i.e., fatty acids factor scores; FAF), milk composition, and udder health in a cohort of 1,158 Italian Brown Swiss cows. The phenotypes under study were 12 FAF previously identified through factor analysis and classified as follows: de novo FA (F1), branchedchain FA-milk yield (F2), biohydrogenation (F3), longchain fatty acids (F4), desaturation (F5), short-chain fatty acids (F6), milk protein and fat contents (F7), odd fatty acids (F8), conjugated linoleic acids (F9), linoleic acid (F10), udder health (F11) and vaccelenic acid (F12). (Co)variance components were estimated for factor scores using a Bayesian linear animal model via Gibbs sampling. The animals were genotyped with the Illumina BovineSNP50 BeadChip v.2 (Illumina Inc., San Diego, CA). A single marker regression model was fitted for GWAS analysis. The gene-set enrichment analysis was run on the GWAS results using the Gene Ontology and the Kyoto Encyclopedia of Genes and Genomes pathway databases to identify the ontologies and pathways associated with the FAF. Marginal posterior means of the heritabilities of the aforementioned FAF ranged from 0.048 for F12 to 0.310 for F5. Factors F1 and F6 had the highest number of relevant genetic correlations with the other traits. The genomic analysis detected a total of 39 significant SNP located on 17 Bos taurus autosomes. All latent variables produced signals except for F2 and F10. The traits with the highest number of significant associations were F11 (17) and F12 (7). Gene-set enrichment analyses identified significant pathways (false discovery rate 5\%) for F3 and F7. In particular, systemic lupus erythematosus was enriched

Received October 17, 2018.

Accepted March 4, 2019.

*Corresponding author: alessio.cecchinato@unipd.it for F3, whereas the MAPK (mitogen-activated protein kinase) signaling pathway was overrepresented for F7. The results support the existence of important and exploitable genetic and genomic variation in these latent explanatory phenotypes. Information acquired might be exploited in selection programs and when designing further studies on the role of the putative candidate genes identified in the regulation of milk composition and udder health.

Key words: factor analysis, fatty acids, udder health, genome-wide association study (GWAS), gene-set enrichment

\section{INTRODUCTION}

Fat is the main energy component of milk and it is known to contain more than 400 individual fatty acids (FA; Månsson et al., 2008). Milk FA derive from de novo synthesis and from the uptake of preformed FA from diet, rumen metabolism, or lipid depot mobilization (Lock and Bauman, 2004). They affect the physical and sensory properties of dairy products (Chen et al., 2004) and contain functional food components that may have beneficial effects for maintaining health and preventing disease (Lock and Bauman, 2004). Milk FA are currently used as biomarkers of different metabolic patterns in animals (e.g., enteric methane emission, ketosis and acidosis status, feed efficiency, lipid mobilization). The possibility of altering milk fat composition through dietary manipulation or selective breeding has, therefore, many implications for the dairy cattle industry. Modification of the milk FA profile in dairy cattle by nutrition, management, or selective breeding may be challenged, however, by the pattern of phenotypic and genetic correlations among individual milk FA (Heck et al., 2012; Pegolo et al., 2016; Hein et al., 2018). This complex network reflects the interrelationships between the various molecular and metabolic pathways involved in the regulation of lipid metabolism in the bovine mammary gland (Bionaz and Loor, 2008; Pegolo et al., 2017). 
Furthermore, FA concentration in milk is strongly related to milk yield and composition and to udder health. Indeed, IMI (e.g., mastitis) generally cause a decrease in milk fat percentage and affect milk fat composition (Schultz, 1977; Kitchen, 1981; Needs and Anderson, 1984). Somatic cell count is currently the gold standard to screen for IMI, although it is affected by numerous factors (e.g., stress, management, the cow's immune system, genetics; Pyörälä, 2003) and does not always correlate with udder infection (Lakic et al., 2009). Various proposals have, therefore, been made to complement SCC with other indicators (e.g., milk lactose, $\mathrm{pH}$, electrical conductivity, minerals) to detect subclinical mastitis (Macciotta et al., 2012; Egger-Danner et al., 2015; Bobbo et al., 2017), and these could be incorporated into selection indices for genetic improvement.

Statistical approaches based on data reduction methods, such as principal components analysis (PCA) and multivariate factor analysis (MFA), may be adopted to elucidate the detailed structure of the pattern of correlations among measured traits and to extract fewer latent explanatory variables, phenotypically independent among them, that could be included as new phenotypes in breeding programs (Macciotta et al., 2004). With respect to dairy cattle, PCA and MFA have been used to study milk FA profile (Fievez et al., 2003; Conte et al., 2016; Mele et al., 2016), milk composition, milk protein profile, and cheese-making properties (Macciotta et al., 2012; Dadousis et al., 2018b). In addition, the genetic parameters of latent variables extracted from milk major components and protein fractions have been estimated, and the genomic regions underlying their variability have been identified (Macciotta et al., 2012; Dadousis et al., 2017, 2018a), providing evidence for their potential use in dairy cattle breeding. A pathwaybased approach in combination with standard singlemarker genome-wide association studies (GWAS) has revealed that some of the genes associated with the extracted latent variables are part of complex, highly connected pathways or biological functions (Dadousis et al., 2017).

Previously, we applied GWAS and network analysis to individual milk FA to explore the genetic basis controlling milk FA variability and identify key regulators for milk FA profile (Pegolo et al., 2017). Herein, we carried out genetic and genomic analyses on latent variables that were previously extracted using MFA from those original phenotypes plus milk production traits and indicators of udder health (FAF; Mele et al., 2016). We hypothesized that using a few synthetic variables might allow us to simplify the interpretation of the relationships among the traits while maintaining the genetic makeup and biological significance of the original phenotypes. Moreover, because factor analysis aims to explain the covariance of a system, extracted latent variables are able to represent whole pathways of FA. Thus, a GWAS carried out using factor scores instead of single FA measurements may provide wider knowledge on the genetic background of FA metabolism. Therefore, the aims of the present study were to (1) estimate the genetic variation and heritabilities for the FAF; (2) infer the additive genetic and herd-date correlations among the FAF; (3) identify the genomic regions associated with the FAF through GWAS analysis; and (4) complement single-marker GWAS with gene-set enrichment analyses to identify the putative biological pathways underlying the variation in the FAF.

\section{MATERIALS AND METHODS}

\section{Animals and Sampling}

This study is part of the Cowability-Cowplus project. Briefly, milk samples were collected once during the evening milking from 1,158 Brown Swiss cows kept in 85 herds located in Trento Province (northeastern Italy) as described in Cipolat-Gotet et al. (2013). The milk samples (with no preservative added) were immediately refrigerated at $4^{\circ} \mathrm{C}$ and transferred to the CheeseMaking Laboratory of the Department of Agronomy, Food, Natural resources, Animals and Environment of the University of Padua (Legnaro, Padua, Italy) for subsequent analyses.

\section{Phenotypes}

Fatty Acids. Details about the FA analyses were reported in Pegolo et al. (2016). Briefly, FAME were prepared by the direct extraction and alkali-catalyzed trans-methylation procedure, previously described by Feng et al. (2004). The FA composition was determined using a ThermoQuest gas chromatograph (Thermo Electron Corp., Waltham, MA) equipped with a flameionization detector and a high polar fused-silica capillary column (Chrompack CP-Sil88 Varian, Middelburg, the Netherlands; $100 \mathrm{~m}, 0.25 \mathrm{~mm}$ i.d.; film thickness $0.20 \mu \mathrm{m})$. The operating conditions of the GC apparatus were as follows: helium carrier gas at a flow rate of $1 \mathrm{~mL} / \mathrm{min}$; split ratio: 1:80; oven temperature: $60^{\circ} \mathrm{C}$ held for $1 \mathrm{~min}$, increased to $173^{\circ} \mathrm{C}$ at $2^{\circ} \mathrm{C} / \mathrm{min}$ and held for $30 \mathrm{~min}$, increased to $185^{\circ} \mathrm{C}$ at $1^{\circ} \mathrm{C} / \mathrm{min}$ and held for $5 \mathrm{~min}$, and finally increased to $220^{\circ} \mathrm{C}$ at $3^{\circ} \mathrm{C} / \mathrm{min}$ and held for $19 \mathrm{~min}$; injector temperature: $270^{\circ} \mathrm{C}$; detector temperature: $300^{\circ} \mathrm{C}$. 
Table 1. Proposed factor names and variables (with proper signs) loaded in each factor (F) according to the factor analysis reported in Mele et al. $(2016)^{1}$

\begin{tabular}{ll}
\hline Latent factors & Traits loaded $^{1}$ (sign) \\
\hline F1: De novo fatty acids (FA) & $8: 0(+), 10: 0(+), 12: 0(+), 14: 0(+)$, C17:0 $(-)$, C17:1c9 $(-)$, C18:1c9 $(-)$ \\
F2: Branched FA-milk yield & Milk yield $(-), 14: 0$ iso $(+), 15: 0$ ante $(+), 15: 0$ iso $(+), 16: 0$ iso $(+), 17: 0$ ante $(+)$ \\
F3: Biohydrogenation & $18: 1 c 12(+), 18: 1$ t $(+), 18: 1$ t16 $(+), 18: 1$ t6 $+t 8(+), 18: 1$ t9 $(+), 18: 2 c 9, c 12(+)$ \\
F4: Long-chain FA & $22: 0(+), 18: 1 t 4(+), 20: 3 c 8, c 11, c 14(+), 20: 4 c 5, c 8, c 11, c 14(+), 20: 5 c 5, c 8, c 11, c 14, c 17(+), 22: 5$ \\
& $c 7, c 10, c 13, c 16, c 19(+)$ \\
F5: Desaturation & $18: 0(-), 10: 1 c 9(+), 14: 1 c 9(+), 16: 1 c 9(+)$ \\
F6: Short-chain FA & $4: 0(+), 6: 0(+), 8: 0(+)$ \\
F7: Milk fat protein & Fat $\%(+)$, Protein $\%(+)$, Casein $\%(+)$ \\
F8: Odd FA & $11: 0(+), 13: 0(+), 15: 0(+)$ \\
F9: CLA & $18: 1 t 11(+), 18: 2 c 9, t 11(+)$ \\
F10: Linolenic & $18: 3 c 9, c 12, c 15(+)$ \\
F11: Udder health & Lactose $\%(-)$, SCS $(+)$ \\
F12: Vaccelenic acid & $18: 2 t 11, c 15(+)$ \\
\hline
\end{tabular}

${ }^{1} c=$ cis, $t=$ trans.

MFA. An MFA was carried out on the correlation matrix of 53 variables consisting of 47 individual FA and 6 milk production and quality traits (milk yield, contents of milk fat, protein, casein, and lactose, and SCS) measured in the 1,158 cows, as detailed in Mele et al. (2016). In brief, the number of extracted factors was selected based on eigenvalues $(>1)$, the relationships with the original variables, and the amount of explained variance. Only variables exhibiting correlations $\geq 0.60$ (absolute value) were included in each factor. In total, 12 latent variables were extracted, which accounted for about $75 \%$ of the total variance. These factors represented specific groups of $\mathrm{FA}$ or biological processes (Table 1): de novo FA (F1), branched FA-milk yield (MY) (F2), biohydrogenation (F3), long-chain fatty acids (F4), desaturation (F5), short-chain fatty acids (F6), milk protein and fat contents (F7), odd FA (F8), CLA (F9), linoleic acid (F10), udder health (F11), and vaccelenic acid (F12).

\section{Genotypes}

The Illumina BovineSNP50 BeadChip v.2 (Illumina Inc., San Diego, CA) was used to genotype 1,152 cows (blood samples were not available for all phenotyped animals). Quality control filtered markers that did not meet the following criteria: (1) call rate $>95 \%$, (2) minor allele frequency $\geq 0.01 \%$, and (3) no extreme deviation from Hardy-Weinberg proportions $(P>0.001$, Bonferroni corrected). In total, 37,568 SNP were considered for subsequent analyses. After filtering for low call rate $(<95 \%), 1,011$ cows were retained.

\section{Genetic Analyses}

Genetic analyses for the 12 FAF were carried out using the following hierarchical model:

$$
\mathbf{y}=\mathbf{X b}+\mathbf{Z}_{1} \mathbf{h}+\mathbf{Z}_{2} \mathbf{a}+\mathbf{e}
$$

where $\mathbf{y}$ is the vector of phenotypic records with dimension $n ; \mathbf{X}, \mathbf{Z}_{1}$, and $\mathbf{Z}_{2}$ are appropriate incidence matrices for systematic effects (b), herd-date effects $(\mathbf{h} ; \mathrm{n}=85)$, and polygenic additive genetic effects $(\mathbf{a})$, respectively. Included in $\mathbf{b}$ are the nongenetic effects of DIM (classes of $30 \mathrm{~d}$ each) and parity (classes 1, 2, $3, \geq 4)$. All analyses were conducted using a standard Bayesian approach. The priors for $\mathbf{b}$ and the variance components were assumed to be flat.

The a priori distributions of $\mathbf{h}$ and $\mathbf{a}$ were assumed multivariate normal, as follows:

$$
p\left(\mathbf{h} \mid \sigma_{h}^{2}\right) \sim N\left(0, \mathbf{I} \sigma_{h}^{2}\right) \text { and } p\left(\mathbf{a} \mid \sigma_{a}^{2}\right) \sim N\left(0, \mathbf{A} \sigma_{a}^{2}\right),
$$

where $\mathbf{I}$ is an identity matrix with dimensions equal to the number of elements in $\mathbf{h}, \mathbf{A}$ is the numerator relationship matrix between individuals (Wright, 1922; the pedigree file contained data on 3,378 animals), and $\sigma_{h}^{2}$ and $\sigma_{a}^{2}$ are the herd-date and additive genetic variances, respectively.

Genetic and herd-date correlations between the variables were estimated through a set of bivariate analyses that implemented model [1] in its multivariate version. In this case, traits were assumed to jointly follow a multivariate normal distribution along with the additive genetic, herd-date, and residual effects.

Marginal posterior distributions of all unknowns were estimated using the Gibbs sampling algorithm [the TM program (http://snp.toulouse.inra.fr/ alegarra) was used for all Gibbs sampling procedures]. Chain lengths and burn-in period were assessed by visual inspection of the trace plots. After a preliminary analysis, we kept the chains of 850,000 samples and used a burn-in pe- 
riod of 50,000, after which 1 in every 100 subsequent samples was retained.

The posterior mean was used as the point estimate for all parameters. Lower and upper bounds of the highest $95 \%$ probability density regions (HPD95) were obtained from the estimated marginal densities and used to estimate heritability. For the correlations, in addition to the means of each marginal posterior distribution, we also estimated the probability of each mean being greater than 0 when the mean is positive, or lower than 0 when the mean is negative $(\mathrm{P})$. All estimates with $\mathrm{P}>95 \%$ were considered "relevant" correlations. A more detailed description of these features can be found in Blasco (2005).

Intra-herd heritability $\left(h^{2}\right)$ was computed as

$$
h^{2}=\frac{\sigma_{a}^{2}}{\sigma_{a}^{2}+\sigma_{e}^{2}},
$$

and herd-date contribution $\left(h_{\text {herd }}\right)$ was computed as

$$
h_{h e r d}=\frac{\sigma_{h}^{2}}{\sigma_{a}^{2}+\sigma_{h}^{2}+\sigma_{e}^{2}} .
$$

\section{GWAS and Pathway Analyses}

GWAS. Genome-wide association analyses were conducted variable by variable using a single-marker regression model implemented in the GenABEL $R$ package (GenABEL, 2013) and the genome-wide association using mixed model and regression-genomic control (GRAMMAR-GC) approach (Amin et al., 2007). First, an additive polygenic model with a genomic relationship matrix was fitted:

$$
\mathbf{y}=\mathbf{X} \boldsymbol{\beta}+\mathbf{a}+\mathbf{e}
$$

where $\mathbf{y}$ is a vector of FAF; $\boldsymbol{\beta}$ is a vector with fixed effects of DIM (classes of $30 \mathrm{~d}$ each), parity of the cow (classes $1,2,3, \geq 4)$ and herd-date $(\mathrm{n}=85)$; and $\mathbf{X}$ is the incidence matrix that associates each observation with specific levels of the factors in $\boldsymbol{\beta}$. The 2 random terms included in the model were animal and residuals, which were assumed to be normally distributed as $\mathbf{a} \sim N\left(0, \mathbf{G} \sigma_{g}^{2}\right)$ and $\mathbf{e} \sim N\left(0, \mathbf{I} \sigma_{e}^{2}\right)$, where $\mathbf{G}$ is the genomic relationship matrix, $\mathbf{I}$ is an identity matrix, and $\sigma_{g}^{2}$ and $\sigma_{e}^{2}$ are the additive genomic and residual variances, respectively. In a second step of the GRAMMARGC, the residuals obtained in model [2] were regressed on the SNP (single marker regression) to test for associations. Finally, the genomic control (GC) approach corrects for the conservativeness of the GRAMMAR procedure and estimates the marker effects (Svishcheva et al., 2012). A $P$-value threshold of $5 \times 10^{-5}$ was adopted to determine significant associations (Burton et al., 2007). The $\mathrm{r}^{2}$ statistic (squared correlation coefficient) was chosen to predict the extent of linkage disequilibrium (LD) using the $\mathrm{R}$ package LDheatmap (Shin et al., 2006).

Gene-Set Enrichment Analysis. A pathway analysis was performed to capture the weaker but related single-variant signals that were missed by standard GWAS because of its stringent $P$-value threshold. It builds on the assumption that complex traits may be controlled by changes in biological pathways or cellular functions in which many highly coordinated genes might each play a modest role.

First, we selected from the GWAS results the relevant SNP based on a nominal $P$-value $(<0.05)$. Then, if these SNP were located within a gene or at a distance $<15 \mathrm{~kb}$ from the coding region (Pickrell et al., 2010) based on the Ensembl Bos taurus UMD 3.1 assembly, they were assigned to the gene using the BiomaRt $\mathrm{R}$ package (Durinck et al., 2005, 2009). We performed an enrichment analysis using the Fisher's exact test with false discovery rate (FDR) correction in the goseq $\mathrm{R}$ package (Young et al., 2010) to identify significantly overrepresented Gene Ontology (GO) terms (Ashburner et al., 2000) and Kyoto Encyclopedia of Genes and Genomes (KEGG) pathways (Ogata et al., 1999; FDR $<0.05)$. Only terms with $>10$ and $<1,000$ genes were included in the analyses to avoid testing broad or narrow functional categories.

\section{RESULTS}

\section{Heritabilities of FAF and Herd Effects}

The means of the marginal posterior densities of variance components, as well as the estimates of heritabilities and effects of herd-date (calculated as the proportion of total phenotypic variance) for the $12 \mathrm{FAF}$ are summarized in Table 2. Factors F5 (desaturation; 0.310 ) and F7 (milk fat protein; 0.271) had the highest heritabilities, whereas F4 (long-chain FA; 0.055), F9 (CLA; 0.056), and F12 (vaccelenic; 0.048) had the lowest. The other FAF had low heritabilities ranging from 0.125 (F8: odd FA) to 0.214 (F2: branched FAMY). Moreover, the amount of variance explained by herd-date was generally moderate or large, with the highest values $(>0.50)$ obtained for F2 (branched FAMY), F3 (biohydrogenation), F4 (long-chain FA), F6 (short-chain FA), F9 (CLA), and F10 (linolenic) and the lowest for F11 (udder health). 


\section{Additive Genetic and Herd-Date Correlations Among FAF}

Point estimates of additive genetic and herd-date correlations among the 12 FAF are shown in Table 3. Overall, 28 genetic correlations (out of the 66 assessed) presented a posterior probability above (positive estimates) or below (negative estimates) 0 , which are considered relevant correlations within a Bayesian framework. Factors F1 (de novo FA) and F6 (shortchain FA) exhibited the highest number of relevant genetic correlations with the other traits. In particular, F1 was strongly and negatively correlated with F3 (biohydrogenation; -0.734) and F5 (desaturation; $-0.707)$; F1 was also correlated negatively, although to a lesser extent, with F8 (odd FA) and F10 (linolenic) and positively with F4 (long-chain FA), F6 (short-chain FA), and F12 (vaccelenic). Factor F6 was positively correlated with F10 (linolenic), F11 (udder health), and F12 (vaccelenic), and negatively with F4 (long-chain FA), F5 (desaturation), F8 (odd FA), and F9 (CLA). Interestingly, F9 was strongly and negatively correlated with F11 (udder health; -0.728). In addition, F11 had moderate negative correlations with F3 (biohydrogenation) and F8 (odd FA) and a moderate positive correlation with F4 (long-chain FA).

Few relevant herd-date correlations were found. In particular, F2 (branched FA-MY) was negatively correlated with F1 (de novo FA) and F7 (milk fat protein). Furthermore, F5 (desaturation) was negatively correlated with F12 (vaccelenic) (Table 3).

\section{GWAS and Pathway Analysis}

GWAS. A summary of the results of the GWAS for the 12 FAF is presented in Table 4. In total, we detected 39 significant SNP located on 17 Bos taurus autosomes. No signal was common to all FAF. The $P$ values ranged from $4.90 \mathrm{E}-05$ to $7.80 \mathrm{E}-13$. Signals were produced by all latent variables except F2 (branched FA-MY) and F10 (linolenic). The traits with highest number of significant associations were F11 (udder health; 17) and F12 (vaccelenic; 7). The chromosomes with the highest number of significant SNP were BTA3 (8) and BTA8 (5). Significant signals were found on BTA3 for 4 traits: F3 (biohydrogenation; at $\sim 74.75$ $\mathrm{Mb}$ ), F8 (odd FA; at $\sim 72.74 \mathrm{Mb}$ ), F11 (udder health; at $\sim 44.36 \mathrm{Mb}$ and at $\sim 84.83$ to $84.89 \mathrm{Mb}$ ) and $\mathrm{F} 12$ (vaccelenic; at $\sim 108.26-110.10 \mathrm{Mb}$ ). On the other hand, all signals located on BTA8 (at $~ 64.09, ~ 81.47$, $\sim 103.28-104.48$, and $\sim 109,06 \mathrm{Mb}$ ) were significant for F11 (udder health). Moreover, 3 significant associations were found on BTA26 (at $\sim 24.60, \sim 33.58$, and $\sim 51.54$ $\mathrm{Mb}$ ) and on BTA28 (at $\sim 35.81$ and $\sim 43.14-43.18 \mathrm{Mb}$ ) for F11. A region of consecutive SNP $(>2)$ was detected on BTA6 ( 81.65-82.71 Mb) for F7 (milk fat protein). Signals were detected on BTA15 for both F4 (longchain FA; at $\sim 40.51 \mathrm{Mb}$ ) and F6 (short-chain FA; at $\sim 52.44-52.47 \mathrm{Mb}$ ). Only 1 SNP was detected on BTA19 (at $\sim 11.40 \mathrm{Mb}$ ) and this was significantly associated with F9 (CLA). Significant associations on BTA20 were detected for both F1 (de novo FA; at $\sim 57.92 \mathrm{Mb}$ ) and F5 (desaturation; at $\sim 51.14 \mathrm{Mb}$ ). The highest signals

Table 2. Estimates ${ }^{1}$ of genetic variance $\left(\sigma_{a}^{2}\right)$, herd-date variance $\left(\sigma_{h}^{2}\right)$, residual variance $\left(\sigma_{e}^{2}\right)$, heritability $\left(h^{2}\right)$, and herd-date variance as proportion of total variance $\left(h_{\text {herd }}\right)$ for the latent factors $(\mathrm{F})^{2}$

\begin{tabular}{|c|c|c|c|c|c|c|}
\hline \multirow[b]{2}{*}{ Item } & \multicolumn{3}{|c|}{ Variance } & \multicolumn{2}{|c|}{ Heritability $^{3}$} & \multirow[b]{2}{*}{$h_{\text {herd }}{ }^{4}$} \\
\hline & $\sigma_{a}^{2}$ & $\sigma_{h}^{2}$ & $\sigma_{e}^{2}$ & $h^{2}$ & HPD95 & \\
\hline F2: Branched FA-milk yield & $0.084(0.03)$ & $0.561(0.09)$ & $0.308(0.03)$ & 0.214 & $0.08 ; 0.37$ & $0.584(0.04)$ \\
\hline F3: Biohydrogenation & $0.079(0.03)$ & $0.614(0.10)$ & $0.329(0.03)$ & 0.193 & $0.05 ; 0.36$ & $0.596(0.04)$ \\
\hline F4: Long-chain FA & $0.024(0.01)$ & $0.610(0.10)$ & $0.415(0.02)$ & 0.055 & $0.00 ; 0.14$ & $0.577(0.4)$ \\
\hline F5: Desaturation & $0.245(0.07)$ & $0.118(0.03)$ & $0.541(0.06)$ & 0.310 & $0.13 ; 0.49$ & $0.129(0.02)$ \\
\hline F8: Odd FA & $0.088(0.04)$ & $0.311(0.05)$ & $0.611(0.04)$ & 0.125 & $0.02 ; 0.26$ & $0.305(0.04)$ \\
\hline F9: CLA & $0.027(0.01)$ & $0.536(0.09)$ & $0.463(0.02)$ & 0.056 & $0.00 ; 0.14$ & $0.518(0.04)$ \\
\hline F10: Linolenic & $0.097(0.04)$ & $0.542(0.09)$ & $0.382(0.03)$ & 0.201 & $0.05 ; 0.39$ & $0.526(0.04)$ \\
\hline F11: Udder health & $0.118(0.06)$ & $0.073(0.02)$ & $0.731(0.06)$ & 0.138 & $0.02 ; 0.30$ & $0.081(0.02)$ \\
\hline F12: Vaccelenic acid & $0.036(0.02)$ & $0.258(0.05)$ & $0.721(0.03)$ & 0.048 & $0.00 ; 0.10$ & $0.251(0.03)$ \\
\hline
\end{tabular}

${ }^{1}$ Estimates are the mean of the marginal posterior density of the parameter. Standard deviations are given within parentheses.

${ }^{2}$ Latent variable defined according to Mele et al. (2016).

${ }^{3}$ Where $h^{2}=\sigma_{a}^{2} / \sigma_{a}^{2}+\sigma_{e}^{2}$, and HPD95 $=$ the highest $95 \%$ probability density regions.

${ }^{4}$ Where $h_{\text {herd }}=\sigma_{h}^{2} / \sigma_{a}^{2}+\sigma_{h}^{2}+\sigma_{e}^{2}$. 


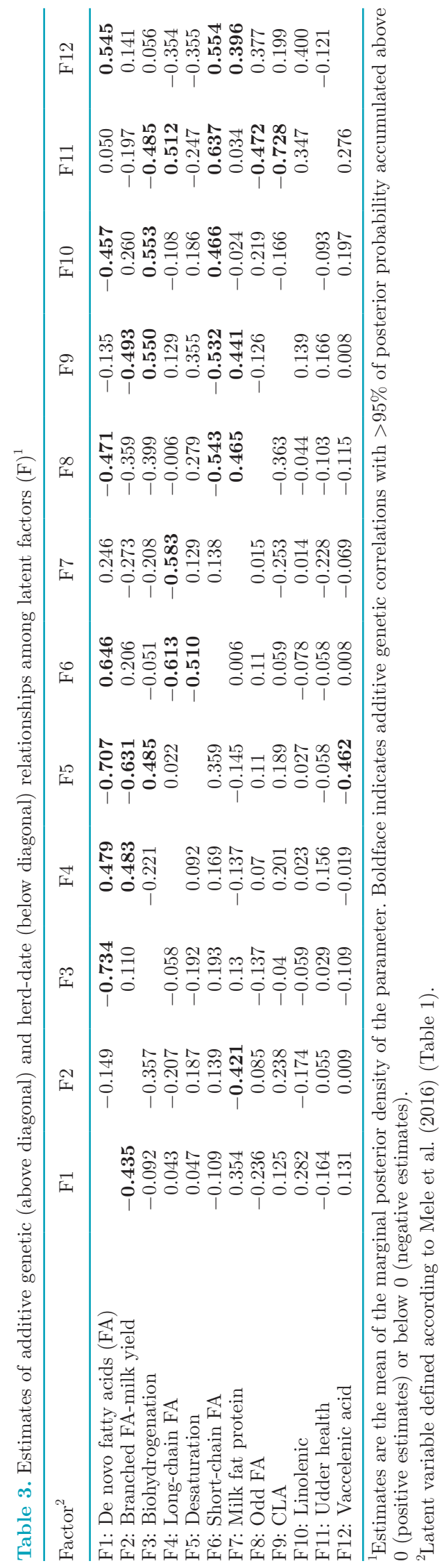

were detected for F11 (udder health) and these corresponded to the markers ARS-BFGL-NGS-33061 $(P=$ 7.80E-13) and ARS-BFGL-NGS-15117 $(P=1.47 \mathrm{E}-08)$, which were located on BTA3 $(\sim 44.34 \mathrm{Mb})$ and BTA8 $(\sim 81.47 \mathrm{Mb})$, respectively. The effects were relatively large for these SNP, around 1.3 to 1.5 standard deviations from the mean (Table 4).

Gene-Set Enrichment Analyses. For each trait, $\sim 850$ SNP identified from the GWAS results $(P<0.05)$ were assigned, on average, to $\sim 700$ genes, which were mined in the goseq package to identify the putative biological functions and pathways that helped explain variability in the FAF. Significantly enriched terms $($ FDR $<0.05)$ were detected only for 2 FAF (Table 5 ): F3 (biohydrogenation) and F7 (milk fat protein). In particular, KEGG analysis revealed that a set of genes pertaining to systemic lupus erythematosus was significantly enriched for F3 (FDR $=0.00023$ ), whereas overrepresentation of MAPK signaling pathway was shown for F7 $(\mathrm{FDR}=0.00018)$.

\section{DISCUSSION}

In this study, we used 12 explanatory latent independent variables that were previously extracted from factor analysis of 53 original inter-correlated traits related to milk composition and udder health (Mele et al., 2016) as synthetic phenotypes for genetic and genomic analyses. This approach substantially reduced computational time and simplified interpretation of the biological significance of the results.

\section{Genetic Analyses}

Overall, heritability estimates of the FAF agreed with those of the individual traits comprising each factor. For instance, the heritability of F1 (de novo FA; 0.144 ) was in line with the estimates for 8:0, 10:0, 12:0, and 14:0 (0.097-0.243) obtained in a previous work (Pegolo et al., 2016). The moderate heritability of F5 (desaturation; 0.310) was comparable to that obtained for 14:1 cis-9 $\left(h^{2}=0.360\right.$; Pegolo et al., 2016), likely reflecting the activity of stearoyl-CoA desaturase 1 (SCD1). Indeed, in the bovine mammary gland, almost all 14:1 cis-9 originates from SCD1 activity (Bernard et al., 2006). The moderate $h^{2}$ of F7 (milk fat protein; 0.271 ) was likely due to the strong genetic background of the protein and casein contents (Schopen et al., 2009; Buitenhuis et al., 2016; Pegolo et al., 2018). The low heritabilities found for F4 (long-chain FA; 0.055) and F9 (CLA; 0.056) were in line with estimates for the individual FA comprising these factors (Pegolo et al., 2016), the variability of which in milk fat is largely 
dependent on environmental effects and particularly on dietary content of these FA (Heck et al., 2012).

Overall, the pattern of genetic correlations was consistent with the biological pathways represented by the 12 FAF; for example, the negative correlation between F4 (long-chain FA) and F6 (short-chain FA) or the positive correlation between F1 (de novo FA) and F6 (shortchain FA). Factor F1 (de novo FA) exhibited strong negative genetic correlations with F3 (biohydrogenation) and F5 (desaturation). Specific biohydrogenation products have been found to be potent inhibitors of milk fat synthesis (Bauman and Griinari, 2001). It has been reported that 18:1 trans-10 strongly reduces the expression of fatty acid synthase $(F A S N), S C D 1$, and sterol regulatory element binding transcription factor 1 (SREBF1) in bovine mammary epithelial cells, pro-

Table 4. Summary results of the genome-wide association analysis on the extracted latent factors $(\mathrm{F})^{1}$

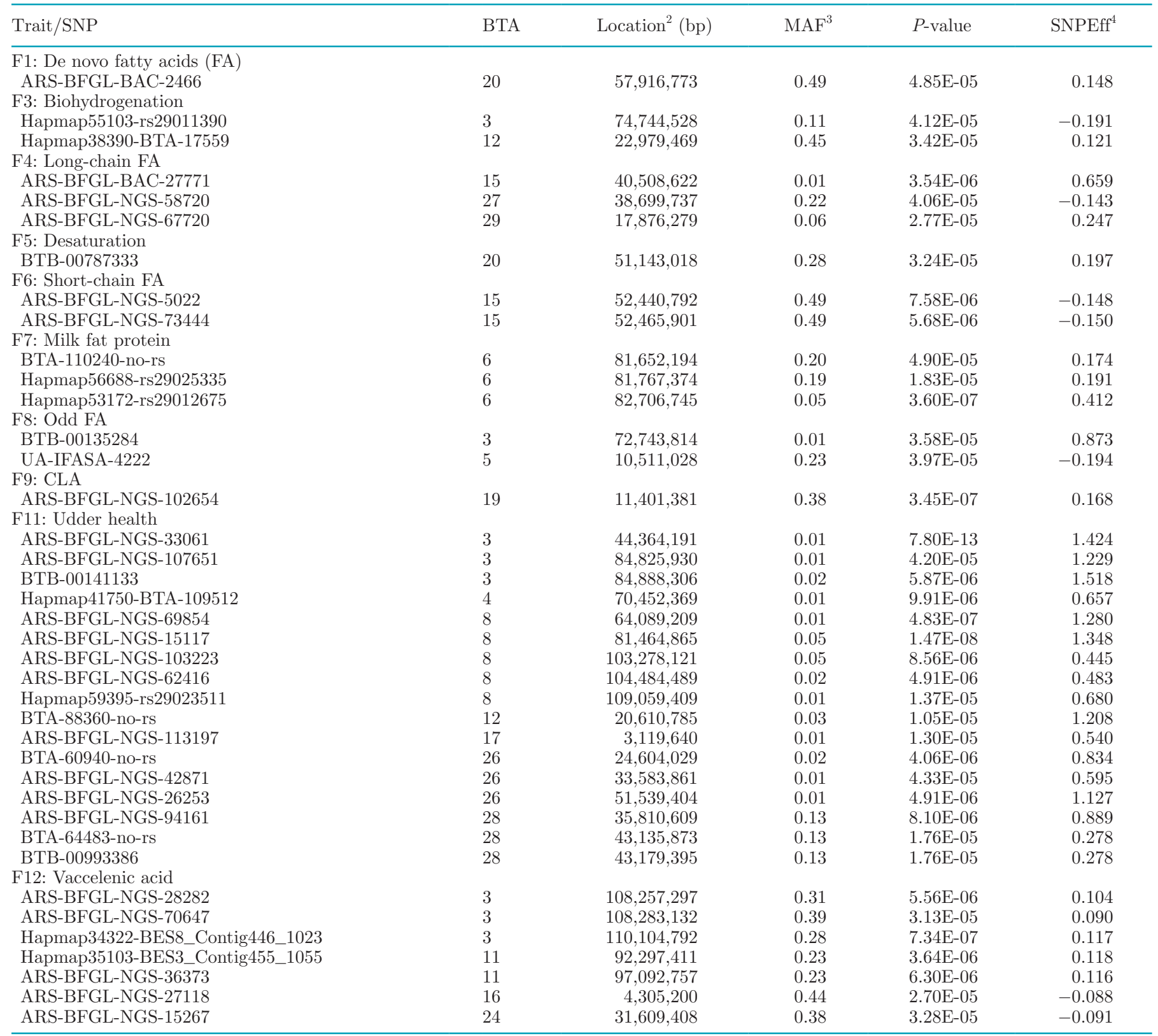

${ }^{1}$ Latent variables defined according to Mele et al. (2016).

${ }^{2}$ Location $=$ SNP position on the chromosome based on the Ensembl Bos taurus UMD3.1 assembly.

${ }^{3} \mathrm{MAF}=$ minor allele frequency.

${ }^{4}$ Effect of the significant SNP; factor scores are standardized with mean of 0 and SD of 1. 
viding support for its potential antilipogenic properties (Kadegowda et al., 2009). In addition, postruminal infusions of a mixture of 18:1 FAME providing $92.1 \mathrm{~g} / \mathrm{d}$ of 18:1 trans-10 to lactating cows reduced the milk fat content and output by approximately $20 \%$ (Shingfield et al., 2009). Several relevant genetic correlations were found between F11 (udder health) and the other FAF, which might provide new insights into the inflammatory response in the bovine mammary gland. Factor F11 was indeed included in this study for consistency with the previous work (Mele et al., 2016) but also because the original phenotypes, together with milk FA, contribute to explain the complexity of the relationships between milk quality and composition, and mammary gland functionality. Factor F11 showed a strong negative genetic correlation with F9 (CLA) and, to a lower extent, with F3 (biohydrogenation) and F8 (odd $\mathrm{FA}$ ). At the same time, a positive genetic correlation was found between F11 and F4 (long-chain FA) and F6 (short-chain FA). High-genetic-merit cows are usually more susceptible to negative energy balance and mastitis, especially in the first part of lactation (Van Knegsel et al., 2014). Therefore, high-grain diets are often administered to cover the higher requirements of net energy for lactation. Previous studies have highlighted that metabolic disorders related to high-grain diets are usually associated with increases in the concentrations of LPS in the rumen and peripheral blood, because of the translocation of LPS from the digestive tract (Khafipour et al., 2009). The inflammatory response induced by circulating LPS has been also associated with several diseases, including mastitis (Zimov et al., 2011). Circulating LPS released from the cell wall of gram-negative bacteria (including bacteria involved in udder infection) or experimentally infused in blood have been proposed as potent modulators of some key genes involved in lipid metabolism such as SREBP1 and SCD1 (Xu et al., 2016; Wang et al., 2018a). More precisely, LPS downregulates both $S C D 1$ and SREBP1 expression, indirectly also affecting the metabolic steps regulated by the genes reported above. Interestingly, F11 was strongly negatively associated with F9 (CLA), which, in turn, was positively associated with the pair 18:1 trans-11 and 18:2 cis-9,trans-11. It is well known that the content of 18:2 cis-9,trans-11 in milk fat strongly depends on mammary desaturation activity. In fact, the endogenous synthesis of 18:2 cis-9,trans-11 from 18:1 trans-11 explains almost $80 \%$ of total 18:2 cis-9,trans-11 in milk fat (Corl et al., 2001). In the case of SREBP1, the downregulating effect of LPS has been associated with a reduction in transcription levels of acetyl-CoA carboxylase-1 and fatty acid synthase in mammary gland. Because these enzymes are responsible for the de novo synthesis of milk FA starting from acetate and butyrate, mastitis and, indirectly, milk SCC should be associated with a reduction of the elongation process of acetate and butyrate to palmitate. This might explain the positive genetic correlation observed between F11 and F6. It is also worth mentioning the positive association between F11 and F4, which is in turn positively associated with very long chain PUFA (both $\mathrm{n}-3$ and $\mathrm{n}-6$ ). Also, in this case, this pattern of association could be related to metabolic changes in mammary gland induced by mammary infection. In fact, the inflammatory response of mammary gland includes a specific group of potent lipid-derived inflam-

Table 5. Significantly enriched Kyoto Encyclopedia of Genes and Genomes (KEGG) pathways using genes associated with the extracted latent factors $^{1}$

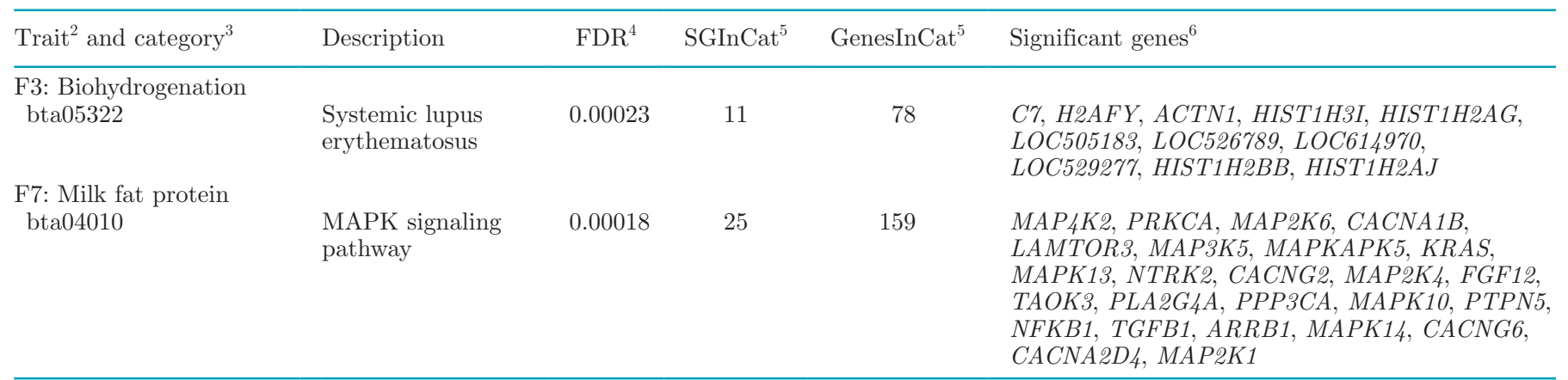

\footnotetext{
${ }^{1}$ Latent variables defined according to Mele et al. (2016).

${ }^{2}$ Only the traits showing significantly enriched terms are reported (false discovery rate $<0.05$ ).

${ }^{3}$ Category $=$ Kyoto Encyclopedia of Genes and Genomes (KEGG) ID.

${ }^{4}$ False discovery rate.

${ }^{5}$ SGInCat $=$ number of significant genes in the category; GenesInCat $=$ number of genes in the category.

${ }^{6} \mathrm{SNP}(P<0.05)$ were assigned to genes if they were located within the gene or in a flanking region of $15 \mathrm{~kb}$ up- and downstream of the gene based on the Ensembl Bos taurus UMD3.1 assembly.
} 
matory mediators called eicosanoids or oxylipids. These molecules are lipid metabolites derived from n- 6 and n-3 PUFA, which are oxygenated through both enzymatic and nonenzymatic pathways (Sordillo, 2018).

The negative genetic correlations among F11 and F3 (biohydrogenation) and F8 (odd FA), which are associated with bacterial FA such as trans FA and odd-chain FA are more difficult to explain and deserve further investigation. Lipopolysaccharides are associated with changes in ruminal bacterial microbiota and disruption of ruminal metabolism in dairy cattle (Jing et al., 2014). Because FA associated with F3 (biohydrogenation) and F8 (odd FA) derived from rumen metabolism, genetic correlations among F11, F3, and F8 might suggest potential interactions between environment and genetic factors.

\section{GWAS, Gene-Set Enrichment, and Pathway- Based Analyses}

Overall, the results obtained overlapped to an extent with previous GWAS analyses carried out on individual milk FA. For instance, the marker ARS-BFGLBAC-2466, which was significantly associated with F1 (de novo FA) was located at $57.91 \mathrm{Mb}$ on BTA20, close to a region $(49.86-55.43 \mathrm{Mb})$ reported to be associated with 12:0 and 14:0 contents in milk fat (Li et al., 2014). The marker ARS-BFGL-NGS-67720, significant for F4 (long-chain FA), was previously found to be associated with 20:4 cis-5,cis-8,cis-11,cis-14 (Pegolo et al., 2017). The 2 significant SNP detected for F8 (odd FA) on BTA3 (BTB-00135284) and BTA5 (UA-IFASA-4222) were previously found to be associated with odd-chain FA (Pegolo et al., 2017). Factor F7 (milk fat protein) generated signals on BTA6, likely confirming the effect of QTL for milk fat and protein (Freyer et al., 2003; Buitenhuis et al., 2016; Pegolo et al., 2018).

The search for genes within the $1-\mathrm{Mb}$ region surrounding the significant SNP detected in the GWAS allowed us to identify putative positional candidate genes for the FAF. For instance, both the markers BTA-110240-no-rs and Hapmap56688-rs29025335, which mapped to BTA6, were significant for F7 (milk fat protein; Table 4) and might have an effect on trans-2,3-enoyl-CoA reductase like (TECRL). In particular, BTA-110240-no-rs corresponded to an intron variant of TECRL, and Hapmap56688-rs29025335 was located $0.1 \mathrm{Mb}$ from the gene. These SNP were in high LD $\left(\mathrm{r}^{2}=0.94\right)$. It has been suggested that this gene plays a role in FA and lipid metabolism, according to the GO and Reactome pathway databases. The marker ARS-BFGL-NGS-67720, which was associated with F4 (long-chain FA), was located on BTA29 at $17.88 \mathrm{Mb}$ and corresponded to an intron variant of the GRB2- associated binding protein 2 (GAB2). The GAB family includes scaffolding/adaptor proteins that recruit cytoplasmic signaling proteins to transduce and integrate signals emanating from growth factors and signaling proteins [e.g., epidermal growth factor (EGF), insulin, and IGF-1; Nishida and Hirano, 2003; Nakaoka and Komuro, 2013], regulating mammary gland growth as well as glucose and lipid metabolism (Bionaz and Loor, 2008, 2011; Rezaei et al., 2016). In addition, FA, in particular UFA, stimulate mammary epithelial cells growth and enhance the effects of other growth factors such as IGF-I and EGF (Hovey et al., 1999). Interestingly, 4 out of the 5 long-chain FA included in F4 (long-chain FA) were unsaturated, the exception being 22:0.

The marker BTB-00787333, associated with F5 (desaturation), mapped $0.4 \mathrm{Mb}$ from the cadherin- 12 precursor $(C D H 12)$. In Holstein cows, this gene is associated with 14:0 and 18:0 contents in milk and with the Wnt signaling pathway (Li et al., 2014), which is reported to control adipogenesis and metabolism (Ross et al., 2000).

The results obtained for F11 (udder health) support the usefulness of this synthetic indicator as a tool for monitoring udder health in dairy cow. Indeed, several significant markers mapped close to genes involved in the immune/stress response or previously associated with mastitis and mastitis indicators (Table 4). For instance, the strong signal detected on BTA8 (ARSBFGL-NGS-15117) was located $50 \mathrm{~kb}$ from growth arrest-specific 1 (GAS1), a positional candidate gene for clinical mastitis in dairy cows (Naderi et al., 2018). The marker ARS-BFGL-NGS-26253 was located on BTA26, $2 \mathrm{~kb}$ from serine/threonine kinase 32C (STK32C). This gene is located within a copy variant region significantly associated with EBV for SCS in Holstein cows (Durán Aguilar et al., 2017). The marker ARS-BFGL-NGS-94161 was located on BTA28, $3 \mathrm{~kb}$ from the pulmonary surfactant-associated protein D $(S F T P D)$ and $30 \mathrm{~kb}$ from the pulmonary surfactantassociated protein A $(M B L 1), 2$ genes that are involved in the innate immune response. Interestingly, a polymorphism in $M B L 1$ has also been associated with SCS in dairy cows, suggesting this gene may play a role in the host's response to mastitis (Wang et al., 2011). The marker ARS-BFGL-NGS-69854, located on BTA8, corresponded to a coding synonymous variant in $\gamma$-aminobutyric acid (GABA) B receptor, 2 (GBBR2); GABA is reported to regulate proliferation and apoptosis as well as LPS-induced inflammation in bovine mammary epithelial cells through the toll-like receptor (TLR) 4 signaling pathway (Wang et al., 2018c). Accordingly, we detected another significant association on BTA8 (Hapmap59395-rs29023511) located $0.2 \mathrm{Mb}$ from the TLR-4 precursor (TLR4). Moreover, a poly- 
morphism in TLR4 has been associated with mastitis resistance in dairy cow (Wang et al., 2007). Finally, the markers ARS-BFGL-NGS-107651 and BTB-00141133 (located at $\sim 84.8 \mathrm{Mb}$ on BTA3) and BTA-64483-no-rs (located at $43.14 \mathrm{Mb}$ in BTA28) mapped close to a QTL for SCS according to the Cattle QTL database. When searching for the nearest genes, we found that ARS-BFGL-NGS-107651 and BTB-00141133 (which were in high $\mathrm{LD}, \mathrm{r}^{2}=0.92$ ) corresponded to intron variants of the nuclear factor IA (NFIA) and BTA-64483no-rs mapped at $25 \mathrm{~Kb}$ from mitogen-activated protein kinase 8 (MAPK8), genes that play a role in immune system (Fazi et al., 2005; Hillreiner et al., 2017).

Pathway analyses showed that systemic lupus erythematosus was significantly enriched for F3 (biohydrogenation). In this disease, autoimmunity and inflammation are associated with pronounced changes in lipid and lipoprotein metabolism, and, in particular, with higher levels of triglycerides and very low density lipoprotein cholesterol (VLDL-C) and lower levels of high-density lipoprotein cholesterol (HDL-C; Borba et al., 2006). Several core histone-coding genes were associated with this pathway; histones are important regulators of gene expression, cell cycle progression, and genome stability (Mei et al., 2017). Variations in the expression of histone variants have been observed in fat-accumulating tissues in mouse models and humans (reviewed by Borghesan et al., 2014). The present results are consistent with a previous GWAS and pathway-based analysis on individual milk FA, which showed that the systemic lupus erythematosus pathway was enriched for trans FA 18:1 (Pegolo et al., 2017). However, the possible link between variation in the genes associated with this pathway and trans-FA metabolism in dairy cows requires further investigation.

Finally, the MAPK signaling pathway was overrepresented for F7 (milk fat protein). The MAP kinases and their downstream targets are involved in mediating cellular responses to extracellular stimuli; they directly mediate the metabolic effects of insulin (Gehart et al., 2010), which plays a crucial role in controlling lipogenesis and protein synthesis in the bovine mammary gland (Bionaz and Loor, 2008, 2011). Accordingly, the MAPK pathway has been associated with the regulation of milk fat and protein metabolism in dairy cattle (Lu et al., 2012; Pegolo et al., 2017; Wang et al., 2018b).

\section{CONCLUSIONS}

The results of the present study show MFA to be an effective tool for reducing complexity in genetic and genomic studies of interrelated phenotypes, while maintaining the biological significance and behavior of the original variables. The genetic variation found in the
12 FAF suggests their possible use as new phenotypes in breeding programs aimed at improving bovine mammary gland functionality and milk quality to reduce the number of traits. Before that, however, further research on a larger population and different breeds is required to validate the results obtained in this study. Finally, in addition to confirming previously identified signals and genes, we found that factors represent a source of novel information about genomic regions and putative candidate genes for milk FA (e.g., TECRL, GAB2) and udder health traits (e.g., GBBR2, MAPK8, NFIA), which are still coherent with the biology of the traits. This information provides a valuable resource for designing further studies on the function of these candidate genes.

\section{ACKNOWLEDGMENTS}

The authors thank the Trento Province (Italy), the Italian Brown Swiss Cattle Breeders Association (ANARB, Verona, Italy), and the Superbrown Consortium of Bolzano and Trento for financial and technical support.

\section{REFERENCES}

Amin, N., C. M. van Duijn, and Y. S. Aulchenko. 2007. A genomic background based method for association analysis in related individuals. PLoS One 2:e1274.

Ashburner, M., C. A. Ball, J. A. Blake, D. Botstein, H. Butler, J. M. Cherry, A. P. Davis, K. Dolinski, S. S. Dwight, J. T. Eppig, M. A. Harris, D. P. Hill, L. Issel-Tarver, A. Kasarskis, S. Lewis, J. C. Matese, J. E. Richardson, M. Ringwald, G. M. Rubin, and G. Sherlock. 2000. Gene Ontology: Tool for the unification of biology. Nat. Genet. 25:25-29.

Bauman, D., and J. Griinari. 2001. Regulation and nutritional manipulation of milk fat: Low-fat milk syndrome. Livest. Prod. Sci. 70:15-29.

Bernard, L., C. Leroux, and Y. Chilliard. 2006. Characterization and nutritional regulation of the main genes in the lactating mammary gland. Pages 295-326 in Ruminant Physiology. K. Sejrsen, T. Hvelplund, and M. O. Nielsen, ed. Wageningen Academic Publisher, Wageningen, the Netherlands.

Bionaz, M., and J. J. Loor. 2008. Gene networks driving bovine milk fat synthesis during the lactation cycle. BMC Genomics 9:366.

Bionaz, M., and J. J. Loor. 2011. Gene networks driving bovine mammary protein synthesis during the lactation cycle. Bioinform. Biol. Insights 5:83-98.

Blasco, A. 2005. The use of Bayesian statistics in meat quality analyses: A review. Meat Sci. 69:115-122.

Bobbo, T., P. L. Ruegg, G. Stocco, E. Fiore, M. Gianesella, M. Morgante, D. Pasotto, G. Bittante, and A. Cecchinato. 2017. Associations between pathogen-specific cases of subclinical mastitis and milk yield, quality, protein composition, and cheese-making traits in dairy cows. J. Dairy Sci. 100:4868-4883.

Borba, E. F., J. F. Carvalho, and E. Bonfá. 2006. Mechanisms of dyslipoproteinemias in systemic lupus erythematosus. Clin. Dev. Immunol. 13:203-208.

Borghesan, M., G. Mazzoccoli, F. Sheedfar, J. Oben, V. Pazienza, and M. Vinciguerra. 2014. Histone variants and lipid metabolism. Biochem. Soc. Trans. 42:1409-1413.

Buitenhuis, B., N. A. Poulsen, G. Gebreyesus, and L. B. Larsen. 2016. Estimation of genetic parameters and detection of chromosomal 
regions affecting the major milk proteins and their post translational modifications in Danish Holstein and Danish Jersey cattle. BMC Genet. 17:114.

Burton, P. R., D. G. Clayton, L. R. Cardon, N. Craddock, P. Deloukas, and A. Duncanson., Wellcome Trust Case Control Consortium, et al. 2007. Genome-wide association study of 14,000 cases of seven common diseases and 3,000 shared controls. Nature 447:661-678.

Chen, S., G. Bobe, S. Zimmerman, E. G. Hammond, C. M. Luhman, T. D. Boylston, A. E. Freeman, and D. C. Beitz. 2004. Physical and sensory properties of dairy products from cows with various milk fatty acid compositions. J. Agric. Food Chem. 52:3422-3428.

Cipolat-Gotet, C., A. Cecchinato, M. De Marchi, and G. Bittante. 2013. Factors affecting variation of different measures of cheese yield and milk nutrient recovery from an individual model cheesemanufacturing process. J. Dairy Sci. 96:7952-7965.

Conte, G., A. Serra, P. Cremonesi, S. Chessa, B. Castiglioni, A. Cappucci, E. Bulleri, and M. Mele. 2016. Investigating mutual relationship among milk fatty acids by multivariate factor analysis in dairy cows. Livest. Sci. 188:124-132.

Corl, B. A., L. H. Baumgard, D. A. Dwyer, J. M. Griinari, B. S. Phillips, and D. E. Bauman. 2001. The role of Delta(9)-desaturase in the production of cis-9, trans-11 CLA. J. Nutr. Biochem. 12:622-630.

Dadousis, C., C. Cipolat-Gotet, G. Bittante, and A. Cecchinato. 2018a. Inferring genetic parameters on latent variables underlying milk yield and quality, protein composition, curd firmness and cheese-making traits in dairy cattle. Animal 12:224-231.

Dadousis, C., C. Cipolat-Gotet, S. Schiavon, G. Bittante, and A. Cecchinato. 2018b. Inferring individual cow effects, dairy system effects and feeding effects on latent variables underlying milk protein composition and cheese-making traits in dairy cattle. J. Dairy Res. 85:87-97.

Dadousis, C., S. Pegolo, G. J. M. Rosa, G. Bittante, and A. Cecchinato. 2017. Genome-wide association and pathway-based analysis using latent variables related to milk protein composition and cheesemaking traits in dairy cattle. J. Dairy Sci. https://doi.org/ 10.3168/jds.2017-13219.

Durán Aguilar, M., S. I. Román Ponce, F. J. Ruiz López, E. González Padilla, C. G. Vásquez Peláez, A. Bagnato, and M. G. Strillacci. 2017. Genome-wide association study for milk somatic cell score in Holstein cattle using copy number variation as markers. J. Anim. Breed. Genet. 134:49-59.

Durinck, S., Y. Moreau, A. Kasprzyk, S. Davis, B. De Moor, A. Brazma, and W. Huber. 2005. BioMart and Bioconductor: A powerful link between biological databases and microarray data analysis. Bioinformatics 21:3439-3440.

Durinck, S., P. T. Spellman, E. Birney, and W. Huber. 2009. Mapping identifiers for the integration of genomic datasets with the $\mathrm{R} / \mathrm{Bio}-$ conductor package biomaRt. Nat. Protoc. 4:1184-1191.

Egger-Danner, C., J. B. Cole, J. E. Pryce, N. Gengler, B. Heringstad, A. Bradley, and K. F. Stock. 2015. Invited review: Overview of new traits and phenotyping strategies in dairy cattle with a focus on functional traits. Animal 9:191-207.

Fazi, F., A. Rosa, A. Fatica, V. Gelmetti, M. L. De Marchis, C. Nervi, and I. Bozzoni. 2005. A minicircuitry comprised of microRNA-223 and transcription factors NFI-A and $\mathrm{C} / \mathrm{EBP} \alpha$ regulates human granulopoiesis. Cell 123:819-831.

Feng, S., A. L. Lock, and P. C. Garnsworthy. 2004. Technical note: A rapid lipid separation method for determining fatty acid composition of milk. J. Dairy Sci. 87:3785-3788.

Fievez, V., B. Vlaeminck, M. S. Dhanoa, and R. J. Dewhurst. 2003 Use of principal component analysis to investigate the origin of heptadecenoic and conjugated linoleic acids in milk. J. Dairy Sci. 86:4047-4053

Freyer, G., P. Sørensen, C. Kühn, R. Weikard, and I. Hoeschele. 2003. Search for pleiotropic QTL on chromosome BTA6 affecting yield traits of milk production. J. Dairy Sci. 86:999-1008.

Gehart, H., S. Kumpf, A. Ittner, and R. Ricci. 2010. MAPK signalling in cellular metabolism: Stress or wellness? EMBO Rep. 11:834-840.
GenABEL. 2013. GenABEL: Genome-wide SNP association analysis. $\mathrm{R}$ package version 1.8-0. https://cran.r-project.org/web/ packages/GenABEL/index.html.

Heck, J. M., H. J. van Valenberg, H. Bovenhuis, J. Dijkstra, and T. C. van Hooijdonk. 2012. Characterization of milk fatty acids based on genetic and herd parameters. J. Dairy Res. 79:39-46.

Hein, L., L. P. Sørensen, M. Kargo, and A. J. Buitenhuis. 2018. Genetic analysis of predicted fatty acid profiles of milk from Danish Holstein and Danish Jersey cattle populations. J. Dairy Sci. 101:2148-2157.

Hillreiner, M., C. Schmautz, I. Ballweg, V. Korenkova, M. W. Pfaffl, and H. Kliem. 2017. Gene expression profiling in pbMEC-In search of molecular biomarkers to predict immunoglobulin production in bovine milk. BMC Vet. Res. 13:369.

Hovey, R. C., T. B. McFadden, and R. M. Akers. 1999. Regulation of mammary gland growth and morphogenesis by the mammary fat pad: A species comparison. J. Mammary Gland Biol. Neoplasia 4:53-68.

Jing, L., R. Zhang, Y. Liu, W. Zhu, and S. Mao. 2014. Intravenous lipopolysaccharide challenge alters ruminal bacterial microbiota and disrupts ruminal metabolism in dairy cattle. Br. J. Nutr. 112:170-182.

Kadegowda, A. K. G., M. Bionaz, L. S. Piperova, R. A. Erdman, and J. J. Loor. 2009. Peroxisome proliferator-activated receptorgamma activation and long-chain fatty acids alter lipogenic gene networks in bovine mammary epithelial cells to various extents. J. Dairy Sci. 92:4276-4289.

Khafipour, E., D. O. Krause, and J. C. Plaizier. 2009. A grain-based subacute ruminal acidosis challenge causes translocation of lipopolysaccharide and triggers inflammation. J. Dairy Sci. 92:10601070 .

Kitchen, B. J. 1981. Review of the progress of dairy science: Bovine mastitis: Milk compositional changes and related diagnostic tests. J. Dairy Res. 48:167-188.

Lakic, B., E. Wredle, K. Svennersten-Sjaunja, and K. Östensson. 2009. Is there a special mechanism behind the changes in somatic cell and polymorphonuclear leukocyte counts, and composition of milk after a single prolonged milking interval in cows? Acta Vet. Scand. 51:4.

Li, C., D. Sun, S. Zhang, S. Wang, X. Wu, Q. Zhang, L. Liu, Y. Li, and L. Qiao. 2014. Genome wide association study identifies 20 novel promising genes associated with milk fatty acid traits in Chinese Holstein. PLoS One 9:e96186. https://doi.org/10.1371/ journal.pone.0096186.

Lock, A. L., and D. E. Bauman. 2004. Modifying milk fat composition of dairy cows to enhance fatty acids beneficial to human health. Lipids 39:1197-1206.

Lu, L.-M., Q.-Z. Li, J.-G. Huang, and X.-J. Gao. 2012. Proteomic and functional analyses reveal MAPK1 regulates milk protein synthesis. Molecules 18:263-275.

Macciotta, N. P. P., A. Cecchinato, M. Mele, and G. Bittante. 2012. Use of multivariate factor analysis to define new indicator variables for milk composition and coagulation properties in Brown Swiss cows. J. Dairy Sci. 95:7346-7354.

Macciotta, N. P. P., D. Vicario, C. Di Mauro, and A. Cappio-Borlino. 2004. A multivariate approach to modeling shapes of individual lactation curves in cattle. J. Dairy Sci. 87:1092-1098.

Månsson, H. L. 2008. Fatty acids in bovine milk fat. Food Nutr. Res. 52. https://doi.org/10.3402/fnr.v52i0.1821.

Mei, Q., J. Huang, W. Chen, J. Tang, C. Xu, Q. Yu, Y. Cheng, L. Ma, $\mathrm{X}$. Yu, and S. Li. 2017. Regulation of DNA replication-coupled histone gene expression. Oncotarget 8:95005-95022.

Mele, M., N. P. P. Macciotta, A. Cecchinato, G. Conte, S. Schiavon, and G. Bittante. 2016. Multivariate factor analysis of detailed milk fatty acid profile: Effects of dairy system, feeding, herd, parity, and stage of lactation. J. Dairy Sci. 99:9820-9833.

Naderi, S., M. Bohlouli, T. Yin, and S. König. 2018. Genomic breeding values, SNP effects and gene identification for disease traits in cow training sets. Anim. Genet. 49:178-192. https://doi.org/10 .1111 /age.12661. 
Nakaoka, Y., and I. Komuro. 2013. Gab docking proteins in cardiovascular disease, cancer, and inflammation. Int. J. Inflam. 2013:141068

Needs, E. C., and M. Anderson. 1984. Lipid composition of milks from cows with experimentally induced mastitis. J. Dairy Res. 51:239-249.

Nishida, K., and T. Hirano. 2003. The role of Gab family scaffolding adapter proteins in the signal transduction of cytokine and growth factor receptors. Cancer Sci. 94:1029-1033.

Ogata, H., S. Goto, K. Sato, W. Fujibuchi, H. Bono, and M. Kanehisa. 1999. KEGG: Kyoto Encyclopedia of Genes and Genomes. Nucleic Acids Res. 27:29-34.

Pegolo, S., A. Cecchinato, J. Casellas, G. Conte, M. Mele, S. Schiavon, and G. Bittante. 2016. Genetic and environmental relationships of detailed milk fatty acids profile determined by gas chromatography in Brown Swiss cows. J. Dairy Sci. 99:1315-1330.

Pegolo, S., C. Dadousis, N. Mach, Y. Ramayo-Caldas, M. Mele, G. Conte, S. Schiavon, G. Bittante, and A. Cecchinato. 2017. SNP co-association and network analyses identify E2F3, KDM5A and BACH2 as key regulators of the bovine milk fatty acid profile. Sci. Rep. 7:17317.

Pegolo, S., N. Mach, Y. Ramayo-Caldas, S. Schiavon, G. Bittante, and A. Cecchinato. 2018. Integration of GWAS, pathway and network analyses reveals novel mechanistic insights into the synthesis of milk proteins in dairy cows. Sci. Rep. 8:566.

Pickrell, J. K., J. C. Marioni, A. A. Pai, J. F. Degner, B. E. Engelhardt, E. Nkadori, J.-B. Veyrieras, M. Stephens, Y. Gilad, and J. K. Pritchard. 2010. Understanding mechanisms underlying human gene expression variation with RNA sequencing. Nature 464:768772 .

Pyörälä, S. 2003. Indicators of inflammation in the diagnosis of mastitis. Vet. Res. 34:565-578.

Rezaei, R., Z. Wu, Y. Hou, F. W. Bazer, and G. Wu. 2016. Amino acids and mammary gland development: nutritional implications for milk production and neonatal growth. J. Anim. Sci. Biotechnol. $7: 20$.

Ross, S. E., N. Hemati, K. A. Longo, C. N. Bennett, P. C. Lucas, R. L. Erickson, and O. A. MacDougald. 2000. Inhibition of adipogenesis by Wnt signaling. Science 289:950-953.

Schopen, G. C. B., J. M. L. Heck, H. Bovenhuis, M. H. P. W. Visker, H. J. F. van Valenberg, and J. A. M. van Arendonk. 2009. Genetic parameters for major milk proteins in Dutch Holstein-Friesians. J. Dairy Sci. 92:1182-1191.

Schultz, L. H. 1977. Somatic cells in milk-Physiological aspects and relationship to amount and composition of milk. J. Food Prot. 40:125-131.

Shin, J.-H., S. Blay, B. McNeney, J. Graham, J.-H. Shin, S. Blay, B. McNeney, and J. Graham. 2006. LDheatmap: An R function for graphical display of pairwise linkage disequilibria between single nucleotide polymorphisms. J. Stat. Softw. 16. https://doi.org/10 $.18637 /$ jss.v016.c03.
Shingfield, K. J., A. Sæbø, P.-C. Sæbø, V. Toivonen, and J. M. Griinari. 2009. Effect of abomasal infusions of a mixture of octadecenoic acids on milk fat synthesis in lactating cows. J. Dairy Sci. 92:4317-4329.

Sordillo, L. M. 2018. Symposium review: Oxylipids and the regulation of bovine mammary inflammatory responses. J. Dairy Sci. 101:5629-5641.

Svishcheva, G. R., T. I. Axenovich, N. M. Belonogova, C. M. van Duijn, and Y. S. Aulchenko. 2012. Rapid variance componentsbased method for whole-genome association analysis. Nat. Genet. 44:1166-1170.

Van Knegsel, A. T. M., H. M. Hammon, U. Bernabucci, G. Bertoni, R. M. Bruckmaier, R. M. A. Goselink, J. J. Gross, B. Kuhla, C. C. Metges, H. K. Parmentier, E. Trevisi, A. Troscher, and A. M. Van Vuuren. 2014. Metabolic adaptation during early lactation: Key to cow health, longevity and a sustainable dairy production chain. Perspect. Agric. Vet. Sci. Nutr. Nat. Resour. 9:002.

Wang, C., M. Liu, Q. Li, Z. Ju, J. Huang, J. Li, H. Wang, and J. Zhong. 2011. Three novel single-nucleotide polymorphisms of MBL1 gene in Chinese native cattle and their associations with milk performance traits. Vet. Immunol. Immunopathol. 139:229-236.

Wang, J., X. Zhang, X. He, B. Yang, H. Wang, X. Shan, C. Li, D. Sun, and R. Wu. 2018a. LPS-induced reduction of triglyceride synthesis and secretion in dairy cow mammary epithelial cells via decreased SREBP1 expression and activity. J. Dairy Res. 85:439-444.

Wang, X., S. Xu, X. Gao, H. Ren, and J. Chen. 2007. Genetic polymorphism of TLR4 gene and correlation with mastitis in cattle. J. Genet. Genomics 34:406-412.

Wang, X., L. Zhang, J. Jin, A. Xia, C. Wang, Y. Cui, B. Qu, Q. Li, and C. Sheng. 2018b. Comparative transcriptome analysis to investigate the potential role of miRNAs in milk protein/fat quality. Sci. Rep. 8:6250.

Wang, Y.-Y., S.-P. Sun, H.-S. Zhu, X.-Q. Jiao, K. Zhong, Y.-J. Guo, G.-M. Zha, L.-Q. Han, G.-Y. Yang, and H.-P. Li. 2018c. GABA regulates the proliferation and apoptosis of MAC-T cells through the LPS-induced TLR4 signaling pathway. Res. Vet. Sci. 118:395402.

Wright, S. 1922. Coefficients of inbreeding and relationship. Am. Nat. $56: 330-338$.

Xu, T., X. Shen, and H. M. Seyfert. 2016. Stearoyl-CoA desaturase 1 expression is downregulated in liver and udder during E. coli mastitis through enhanced expression of repressive C/EBP factors and reduced expression of the inducer SREBP1A. BMC Mol. Biol. 17:16.

Young, M. D., M. J. Wakefield, G. K. Smyth, and A. Oshlack. 2010 Gene ontology analysis for RNA-seq: Accounting for selection bias. Genome Biol. 11:R14.

Zimov, J. L., N. A. Botheras, W. P. Weiss, and J. S. Hogan. 2011. Associations among behavioural and acute physiologic responses to lipo-polysaccharide-induced clinical mastitis in lactating dairy cows. Am. J. Vet. Res. 72:620-627. 